\title{
Health related selection and death rates in the United Kingdom Atomic Energy Authority workforce
}

\author{
Lucy Carpenter, Valerie Beral, Patricia Fraser, Margaret Booth
}

\begin{abstract}
Follow up data on 37355 employees of the United Kingdom Atomic Energy Authority (UKAEA) for the period 1946-79 were analysed to investigate the extent to which selection for work on the basis of health affected subsequent death rates. Causes of death were grouped into two broad categories for analysis: all cancers and all other causes of death. Evidence for an effect of selection of healthy individuals into the workforce was sought primarily by examining standardised mortality ratios (SMRs) by period since recruitment. SMRs for both categories were particularly low during the first two years after recruitment (SMR $=69,95 \%$ confidence interval $(\mathrm{CI})$ 48-97 for all cancers; $\mathrm{SMR}=55,95 \%$ CI $44-69$ for all other causes of death). SMRs for all cancers did not increase significantly with period since recruitment $\left(\chi^{2}\right.$ for trend $=0.4, p=0.53$ ) but did increase for causes of death other than cancer $\left(\chi^{2}\right.$ for trend $\left.=11.1, p=0.001\right)$. Although adjustment for social class strengthened the association between death from causes other than cancer and period since recruitment $\left(\chi^{2}\right.$ for trend $=18.8, p<0.001$ ), simultaneous adjustment for all confounding factors considered (age at death, sex, calendar period of death, geographical location of the workforce, and social class) produced results broadly similar to those obtained from the unadjusted analyses for both cause of death categories. SMRs remained low even after 25 years of follow up $(S M R=84,95 \%$ CI 69-101 for all cancers; $S M R=81,95 \%$ CI 72-91 for all other causes of death).The persistently low SMRs observed in this workforce are unlikely to be due to the selection of healthy individuals
\end{abstract}

Epidemiological Monitoring Unit, Department of Epidemiology \& Population Sciences, London School of Hygiene \& Tropical Medicine, London, WC1 7HT

L Carpenter, P Fraser, M Booth

Imperial Cancer Research Fund, Cancer Epidemiology and Clinical Trials Unit, University of Oxford, Radcliffe Infirmary, Oxford, OX2 6HE

V Beral at the time of recruitment but may be due to $\overrightarrow{\mathcal{N}}$ differences in sociodemographic and lifestyle $\bigcirc$ characteristics. The effect on mortality of 3 selection of individuals out of the workforce due to ill health was also examined. SMRs were. particularly high for both categories in thei first two years after termination of employ- $-\infty$ ment in individuals who left before normalo retirement age $(S M R=167,95 \%$ CI 131-211 for all cancers; $S M R=149,95 \%$ CI $128-173$ for $>$ all other causes of death). In comparison, death rates for the subsequent three years after $\overrightarrow{0}$ termination of employment were lower@ (SMR $=89,95 \%$ CI 67-115 for all cancers, SMR $=99,95 \%$ CI 85-115 for all other causes of death). Apart from this initial fall, there was little evidence of a systematic increase or decrease in mortality with increasing period

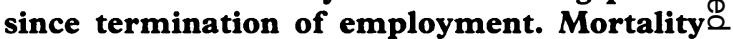
was not significantly associated with duration $\overrightarrow{\hat{O}}$ of employment for either cause of death 3 category either before or after adjustment for confounding factors. Whereas selection of individuals into or out of the workforce on the $\bar{\circ}$ basis of health affects the way in which death 3 rates change with time, other factors such as 0 sociodemographic characteristics or health related behaviour determine the general level of mortality in the longer term. The persistently low SMRs observed in this workforce? throughout the follow up period suggest that selection on the latter factors are likely to have had a considerable effect on death rates in the UKAEA workforce.

When interpreting the results of an occupational 0 mortality study the effect of selection of the workforce is often an important consideration. In- $\frac{\sim}{\Phi}$ dividuals are selected for employment on the basis of $\stackrel{\oplus}{+}$ many factors, not the least of which is their ability to 0 perform certain types of work. One aspect of the $\bar{O}$ process relates to the selection of individuals on the $\stackrel{\mathbb{D}}{\circ}$ basis of their health. In this respect individuals are $\mathbb{\otimes}$ partly self selected insofar as they must be sufficient- $\frac{\sigma}{\sigma}$ ly healthy to seek work but may also be selected by the employer where, for example, pre-employment 8 medical checks are performed. The selection process 
may also take health into account indirectly by selecting individuals on the basis of other factors that are health related, such as marital status, history of psychiatric illness, or alcoholism. The general population includes employed people as well as people who are too sick to seek work or who have been refused employment on health grounds. Consequently, calculation of standardised mortality ratios (SMRs) where expected deaths are obtained using national rates often results in values below 100 . The term "healthy worker effect" is widely used to describe this phenomenon, ${ }^{1-6}$ although some refer to it as selection or comparison bias ${ }^{78}$ or simply to confounding. ${ }^{39}$ It is of concern because adverse effects of exposures at work may be wholly or partly masked by an apparent deficit in mortality in the workforce.

Several factors have been identified as contributing to low SMRs often observed in occupational cohort studies. SMRs are usually lowest of all in the period shortly following recruitment, ${ }^{1-4}$ in young employees, ${ }^{12}$ in those who remain in employment for a relatively long period, ${ }^{1011}$ and in employees of higher social class. ${ }^{112}$ The extent of deficits in mortality compared with the national average also varies according to cause of death, with SMRs for diseases with a chronic course, such as chronic respiratory disease, tending to be lower than for diseases such as cancer which often take a more acute and relatively rapid course. Published data by specific causes of death, however, are few. ${ }^{1-312}$ The characteristic most often attributed to the healthy worker effect is that the deficit in mortality becomes less apparent, or "wears off," as period since recruitment increases. ${ }^{1-612}$ This observation might suggest that the healthy worker effect could be minimised in an analysis by ignoring an initial period following recruitment. This is not an ideal solution, however, since any immediate effects of employment on mortality might then be missed. Furthermore, because the time course of the wearing off is not well understood, it is often not clear how long a period should be ignored.

Factors contributing to deficits in mortality of workforces have been divided into two general categories $^{313}$ - those associated with the initial selection of healthy individuals and those associated with sociodemographic differences between the workforce and the general population. The effects of initial selection on the basis of health are thought to change with time. ${ }^{14}$ In contrast, the effects of sociodemographic characteristics of a workforce are less likely to vary over time and are often important predictors of the underlying death rates of a workforce. ${ }^{13}$ Moreover, whereas sociodemographic factors vary greatly between workforces, the effect that the initial selection of healthy individuals has on death rates may be similar for different workforces. Study- ing the way in which death rates change with time since recruitment is therefore most appropriate for understanding the way in which the initial health related selection process operates.

When discussing the selection of individuals on the basis of health in the employment process, a distinction is sometimes made between a "population selection effect" and a "survivor effect."1 1016 The population selection effect refers to the initial selection of healthy individuals into a workforce. As described above, this is usually investigated by examining the way in which death rates change with period since recruitment. The survivor effect refers to the retention in the workforce of healthy individuals or, conversely, the selective removal from the workforce of the sick. ${ }^{16}$ The survivor effect is often manifest by the relatively low mortality of employees who remain in employment compared with those that leave ${ }^{1011}$ and might therefore be assessed by an examination of SMRs according to duration of employment. An alternative approach is to examine the way in which death rates change after termination of employment. A difficulty in analyses of mortality according to factors such as period since recruitment is that they may be subject to confounding by other time dependent variables. ${ }^{361115}$ For example, both age and period since recuitment may be associated with the level of mortality of a workforce when compared with general population rates, but age and period since recruitment are correlated because there are more recent recruits among younger workers than among older employees.

We examine here the effect of health related selection on death rates in a cohort of employees in the nuclear industry while taking into account the problem of confounding described above. Because of the potential for radiation to induce cancer, two broad categories of cause of death are examined-all cancers and all other causes of death.

\section{Material and methods}

The cohort discussed here consists of all employees of the United Kingdom Atomic Energy Authority (UKAEA) who were first recruited between 1946, when the Authority started operations, and 1979. The characteristics of the workforce and its mortality in relation to radiation exposure have been described in detail elsewhere. ${ }^{17-19}$ In general, workers who had been monitored for exposure to radiation experienced similar death rates to those of other workers. ${ }^{18-20}$ Moreover, increasing exposure to radiation had little or no effect on overall death rates; the only statistically significant finding was an increase in mortality from prostatic cancer with increasing levels of radiation exposure. ${ }^{18}$ The data presented here relate to 37355 employees who had a single period of continuous employment with the UKAEA. These con- 
stitute $94 \%$ of the original workforce analysed.

Person-years at risk were calculated using standard methods. ${ }^{21}$ Observed deaths and person-years at risk were stratified by different levels of the following variables: age at death in five year age groups (15-19, $20-24, \ldots, \geqslant 85)$, sex, calendar period of death (1946-9, 1950-4, . . 1975-9), UKAEA establishment (Dounreay, Harwell, and associated establishments at Culham and London, and Winfrith), social class in six categories using the Registrar General's classification, ${ }^{22}$ age at recruitment in ten year age groups $(<24,25-34, \ldots \geqslant 65)$, period of recruitment $(1946-9,1950-4, \ldots 1970-9)$, period since recruitment ( $<2$ years, $2-4,5-9, \ldots \geqslant 25$ ), duration of employment $(<2$ years, $2-4,5-9, \ldots \geqslant 25)$, and period since termination of employment $(<2$ years, $2-4,5-9, \ldots \geqslant 25)$. Age at death, calendar period of death, period since recruitment, duration of employment, and period since termination of employment were treated as time dependent variables in the person-years at risk calculations. ${ }^{21}$ Expected deaths were calculated for all cancers (ICD 140 209) and all other causes of death (ICD 000-139, 210-999), using the 8th revision of the International
Classification of Diseases, ${ }^{23}$ by applying five year age,. calendar period, and sex specific death rates for $\overrightarrow{\vec{F}}$ England and Wales to the stratified person-years at risk. SMRs were obtained by taking the ratio of the observed to expected deaths and multiplying by 100 . Ninety five per cent confidence intervals for SMRs were based on the Poisson distribution ${ }^{24}$ unless $\varnothing$ deaths exceeded 200, where confidence limits were $\omega$ obtained using the Normal approximation. For each $\overrightarrow{0}$ factor, approximate $k$ degree of freedom chi-squared statistics were obtained to test for differences be- $\vec{\omega}$ tween stratum specific SMRs by comparing the fit of $\frac{\rho}{\circ}$ linear models with and without terms representing $\mathbb{D}$ the factor. The models assumed that the observed deaths in each stratum followed the Poisson distribution with mean equal to the expected deaths and were $\vec{i}$ fitted by maximum likelihood using the computer $\stackrel{\infty}{\infty}$ package GLIM $^{25}$ as described by McCullagh and $ᄋ$ Nelder ${ }^{26}$ and Breslow et al. ${ }^{27}$ Where appropriate, a one degree of freedom approximate $\chi^{2}$ test for trend $\vec{D}$ across the strata of a particular factor was obtained. These resulted from fitting further linear models $\overrightarrow{0}$ after assigning appropriate scores to each stratum of $\emptyset$ the factor and treating them as continuous variables

Table 1 Standardised mortality ratios (SMR) and observed deaths (O) from all cancers and all other causes of death in the UKAEA workforce, 1946-79, by age, sex, calendar period of death, UKAEA establishment, and social class

\begin{tabular}{|c|c|c|c|c|}
\hline & \multicolumn{2}{|c|}{ Cancer mortality } & \multicolumn{2}{|c|}{ All other causes of death } \\
\hline & $S M R$ & (O) & $S M R$ & (O) \\
\hline $\begin{array}{l}\text { Age at death }(y) \\
<35 \\
35- \\
45- \\
55- \\
65- \\
75- \\
\chi^{2} \text { for trend }(\mathrm{df}=1) \\
\chi^{2} \text { for departures from trend }(\mathrm{df}=4)\end{array}$ & $\begin{array}{r}75 \cdot 9 \\
79 \cdot 4 \\
66 \cdot 8 \\
79 \cdot 5 \\
95 \cdot 2 \\
104 \cdot 9 \\
13 \cdot 2 \\
5 \cdot 5\end{array}$ & $\begin{array}{l}(26) \\
(61) \\
(141) \\
(288) \\
(295) \\
(106) \\
(p<0.001) \\
(p=0.24)\end{array}$ & $\begin{array}{r}65 \cdot 4 \\
67 \cdot 6 \\
67 \cdot 3 \\
77 \cdot 6 \\
81 \cdot 9 \\
82 \cdot 2 \\
14 \cdot 5 \\
2 \cdot 5\end{array}$ & $\begin{array}{l}(120) \\
(157) \\
(342) \\
(654) \\
(748) \\
(403) \\
(\mathrm{p}<0.001) \\
(\mathrm{p}=0.64)\end{array}$ \\
\hline $\begin{array}{l}\text { Sex } \\
\text { Men } \\
\text { Women } \\
\chi^{2} \text { for heterogeneity }(\mathrm{df}=1)\end{array}$ & $\begin{array}{r}82.5 \\
89.7 \\
0.9\end{array}$ & $\begin{array}{l}(754) \\
(163) \\
(p=0.34)\end{array}$ & $\begin{array}{r}77.5 \\
68.8 \\
3.4\end{array}$ & $\begin{array}{l}(2164) \\
(260) \\
(p=0.07)\end{array}$ \\
\hline $\begin{array}{l}\text { Calendar period of death } \\
<1954- \\
1955- \\
1960- \\
1965- \\
1970- \\
1975- \\
\chi^{2} \text { for trend }(\mathrm{df}=1) \\
\chi^{2} \text { for departures from trend }(\mathrm{df}=4)\end{array}$ & $\begin{array}{r}61 \cdot 5 \\
98 \cdot 0 \\
76 \cdot 7 \\
83 \cdot 1 \\
77 \cdot 5 \\
90 \cdot 4 \\
1 \cdot 1 \\
6 \cdot 4\end{array}$ & $\begin{array}{l}(18) \\
(64) \\
(99) \\
(170) \\
(224) \\
(342) \\
(\mathrm{p}=0 \cdot 29) \\
(\mathrm{p}=0 \cdot 17)\end{array}$ & $\begin{array}{r}49 \cdot 1 \\
63 \cdot 8 \\
73 \cdot 6 \\
80 \cdot 8 \\
77 \cdot 1 \\
80 \cdot 1 \\
11 \cdot 8 \\
8 \cdot 8\end{array}$ & $\begin{array}{l}(54) \\
(132) \\
(290) \\
(464) \\
(651) \\
(833) \\
(\mathrm{p}=0.001) \\
(\mathrm{p}=0.07)\end{array}$ \\
\hline $\begin{array}{l}\text { UKAEA establishment } \\
\text { Dounreay } \\
\text { Harwell, Culham, and London } \\
\text { Winfrith } \\
\chi^{2} \text { for heterogeneity }(\mathrm{df}=2)\end{array}$ & $\begin{array}{r}67 \cdot 5 \\
85 \cdot 3 \\
91 \cdot 8 \\
5 \cdot 9\end{array}$ & $\begin{array}{l}(95) \\
(709) \\
(113) \\
(p=0.05)\end{array}$ & $\begin{array}{l}96 \cdot 0 \\
74 \cdot 1 \\
70 \cdot 6 \\
21 \cdot 7\end{array}$ & $\begin{array}{l}(380) \\
(1808) \\
(236) \\
(\mathrm{p}<0.001)\end{array}$ \\
\hline $\begin{array}{l}\text { Social class } \\
\text { I }+ \text { II } \\
\text { III } \\
\text { IV }+ \text { V } \\
\chi^{2} \text { for heterogeniety }(\mathrm{df}=2)\end{array}$ & $\begin{array}{l}62 \cdot 6 \\
86 \cdot 6 \\
92 \cdot 8 \\
20 \cdot 3\end{array}$ & $\begin{array}{l}(165) \\
(278) \\
(474) \\
(p<0.001)\end{array}$ & $\begin{array}{l}55 \cdot 6 \\
76 \cdot 5 \\
87 \cdot 2 \\
70 \cdot 4\end{array}$ & $\begin{array}{l}(431) \\
(677) \\
(1316) \\
(\mathrm{p}<0.001)\end{array}$ \\
\hline
\end{tabular}


in the analysis. In these cases the global $\mathrm{k}$ degree of freedom $\chi^{2}$ statistic was divided into a one degree of freedom statistic for trend and a k-1 degree of freedom statistic for departures from trend.

Multivariate analyses were performed to assess the association between mortality and a specific factor of interest after adjusting for the effect of one or more potential confounding factors. Observed and expected deaths were obtained for strata defined by the joint levels of the factor of interest and each of the confounding factors. Linear models were then fitted with terms representing all the factors. From these last models, stratum specific relative standardised mortality ratios (RSMR) (relative to the rate in the lowest stratum) were estimated for the factor of interest adjusted by the effects of the confounding factors included in the model. Approximate $95 \%$ confidence intervals for RSMRs were obtained using the standard errors of coefficients in the fitted model.

\section{Results}

Table 1 gives the SMRs for all cancers and all other causes of death by age at death, sex, calendar period of death, UKAEA establishment, and social class. For age at death and social class, there was a statistically significant trend in SMR for both categories of causes of death. SMRs were lower in the younger age groups and for those in social classes I and II. SMRs increased significantly with calendar period of death for causes of death other than cancer but not for deaths from cancer. There were no significant differences between SMRs for men and women in either cause of death category. There were statistically significant differences between SMRs across establishments for causes other than cancer, with Dounreay having the highest SMR. For all cancers, however, Dounreay had the lowest SMR, the differences between cancer SMRs being of marginal significance.

Table 2 gives SMRs by period since recruitment, duration of employment, age at recruitment, and period of recruitment. For mortality from all cancers and all other causes of death, the trends in SMRs were highly significant for age at recruitment. The

Table 2 SMRs and observed deaths (O) from all cancers and all other causes of death in the UKAEA workforce, 1946-79, by period since recruitment, duration of employment, age at recruitment, and period of recruitment

\begin{tabular}{|c|c|c|c|c|}
\hline & \multicolumn{2}{|c|}{ Cancer mortality } & \multicolumn{2}{|c|}{ All other causes of death } \\
\hline & $S M R$ & $(O)$ & $S M R$ & $(0)$ \\
\hline $\begin{array}{l}\text { Period since recruitment }(y) \\
<2 \\
2- \\
5- \\
10- \\
15- \\
20- \\
25- \\
\chi^{2} \text { for trend }(\mathrm{df}=1) \\
\chi^{2} \text { for departures from trend }(\mathrm{df}=5)\end{array}$ & $\begin{array}{r}69 \cdot 1 \\
82 \cdot 2 \\
79 \cdot 7 \\
92 \cdot 5 \\
78 \cdot 4 \\
88 \cdot 2 \\
84 \cdot 0 \\
0 \cdot 4 \\
4 \cdot 6\end{array}$ & $\begin{array}{l}(33) \\
(70) \\
(145) \\
(213) \\
(192) \\
(157) \\
(107) \\
(p=0.53) \\
(p=0.47)\end{array}$ & $\begin{array}{r}55 \cdot 5 \\
70 \cdot 5 \\
73 \cdot 1 \\
73 \cdot 8 \\
83 \cdot 5 \\
79 \cdot 4 \\
81 \cdot 3 \\
11 \cdot 1 \\
7 \cdot 5\end{array}$ & $\begin{array}{l}(86) \\
(180) \\
(377) \\
(477) \\
(583) \\
(419) \\
(302) \\
(p=0.001) \\
(p=0.19)\end{array}$ \\
\hline $\begin{array}{l}\text { Duration of employment }(y) \\
<2 \\
2- \\
5- \\
10- \\
15- \\
20- \\
25- \\
\chi^{2} \text { for trend }(\mathrm{df}=1) \\
\chi^{2} \text { for departures from trend }(\mathrm{df}=5)\end{array}$ & $\begin{array}{r}81 \cdot 4 \\
80 \cdot 7 \\
89 \cdot 8 \\
85 \cdot 1 \\
82 \cdot 9 \\
88 \cdot 5 \\
57 \cdot 7 \\
0 \cdot 0 \\
4 \cdot 3\end{array}$ & $\begin{array}{l}(214) \\
(152) \\
(215) \\
(162) \\
(100) \\
(57) \\
(17) \\
(p=0.84) \\
(p=0.51)\end{array}$ & $\begin{array}{r}79 \cdot 3 \\
74 \cdot 5 \\
77 \cdot 8 \\
74 \cdot 8 \\
75 \cdot 3 \\
75 \cdot 2 \\
70 \cdot 3 \\
0 \cdot 8 \\
1 \cdot 1\end{array}$ & $\begin{array}{l}(597) \\
(420) \\
(569) \\
(420) \\
(244) \\
(124) \\
(50) \\
(p=0.37) \\
(p=0.95)\end{array}$ \\
\hline $\begin{array}{l}\text { Age at recruitment } \\
<25 \\
25- \\
35- \\
45- \\
55- \\
65- \\
\chi^{2} \text { for trend }(\mathrm{df}=1) \\
\chi^{2} \text { for departures from trend }(\mathrm{df}=4)\end{array}$ & $\begin{array}{r}60 \cdot 6 \\
71 \cdot 7 \\
78 \cdot 2 \\
88 \cdot 8 \\
93 \cdot 7 \\
127 \cdot 0 \\
15 \cdot 9 \\
1 \cdot 2\end{array}$ & $\begin{array}{l}(45) \\
(114) \\
(202) \\
(313) \\
(214) \\
(29) \\
(p<0.001) \\
(p=0.88)\end{array}$ & $\begin{array}{r}65 \cdot 9 \\
67 \cdot 7 \\
77 \cdot 9 \\
80 \cdot 9 \\
78 \cdot 3 \\
76 \cdot 9 \\
6 \cdot 7 \\
4 \cdot 9\end{array}$ & $\begin{array}{l}(174) \\
(295) \\
(485) \\
(757) \\
(623) \\
(90) \\
(p=0.01) \\
(p=0.30)\end{array}$ \\
\hline $\begin{array}{l}\text { Period of recruitment } \\
<1950 \\
\quad 1950- \\
1955- \\
\quad 1960- \\
1965- \\
1970- \\
\chi^{2} \text { for trend }(\mathrm{df}=1) \\
\chi^{2} \text { for departures from trend }(\mathrm{df}=4)\end{array}$ & $\begin{array}{r}81 \cdot 9 \\
87 \cdot 6 \\
75 \cdot 9 \\
92 \cdot 1 \\
106 \cdot 0 \\
56 \cdot 6 \\
0.5 \\
9 \cdot 7\end{array}$ & $\begin{array}{l}(202) \\
(206) \\
(274) \\
(153) \\
(71) \\
(11) \\
(p=0.48) \\
(p=0.05)\end{array}$ & $\begin{array}{r}79 \cdot 6 \\
69 \cdot 7 \\
79 \cdot 2 \\
78 \cdot 0 \\
72 \cdot 1 \\
72 \cdot 9 \\
0 \cdot 0 \\
7 \cdot 2\end{array}$ & $\begin{array}{l}(601) \\
(505) \\
(808) \\
(342) \\
(128) \\
(40) \\
(p=0.92) \\
(p=0.13)\end{array}$ \\
\hline
\end{tabular}




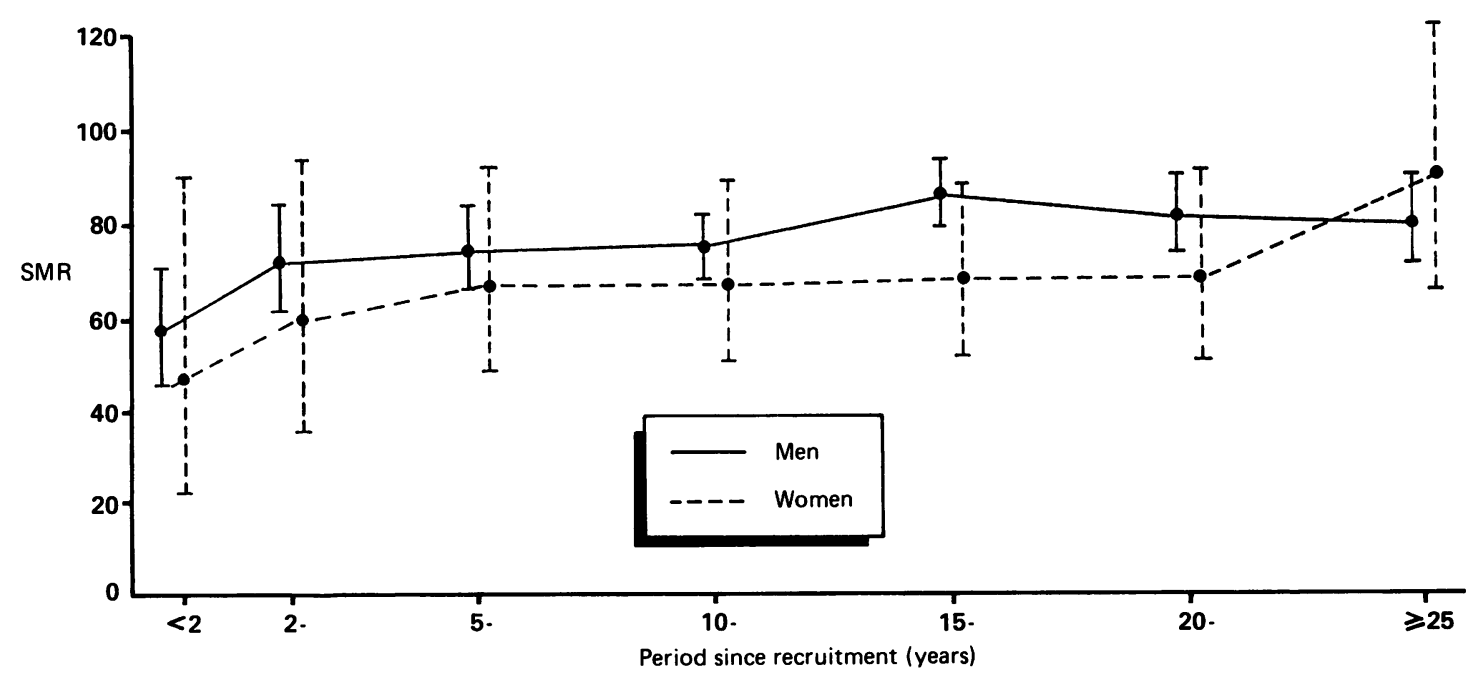

Figure 1 Standardised mortality ratios (with $95 \%$ confidence intervals) for all causes of death except cancer by period since recruitment and sex.

significance of the trend for cancer mortality was only slightly reduced when recruits aged 65 and over were excluded $\left(\chi^{2}\right.$ for trend $\left.=12.2, \mathrm{p}<0.001\right)$. SMRs for causes of death other than cancer also increased significantly with period since recruitment. By contrast, there was little evidence of a trend in cancer mortality with increasing period since recruitment, although the lowest SMR was observed in the first two years after recruitment. During this period, mortality in the workforce was $31 \%$ lower than national rates for all cancers $(S M R=69,95 \%$ CI 48-97) and 44\% lower for all other causes of death $(\mathrm{SMR}=55,95 \%$ CI 44-69). SMRs were lowest in individuals employed for longest although, overall, there was no statistically significant association between duration of employment and mortality for either cause of death category. SMRs for cancer mortality, but not for deaths from other causes, varied according to period of recruitment strata, the differences being of marginal statistical significance.

Figures 1 and 2 show SMRs for all causes of death other than cancer by period since recruitment separately by sex and social class. The general pattern of increasing SMR with period since recruitment was observed in male and female employees (fig 1), although SMRs for women were below those of men in each stratum except the last. The increase in SMR with period since recruitment was also gen-

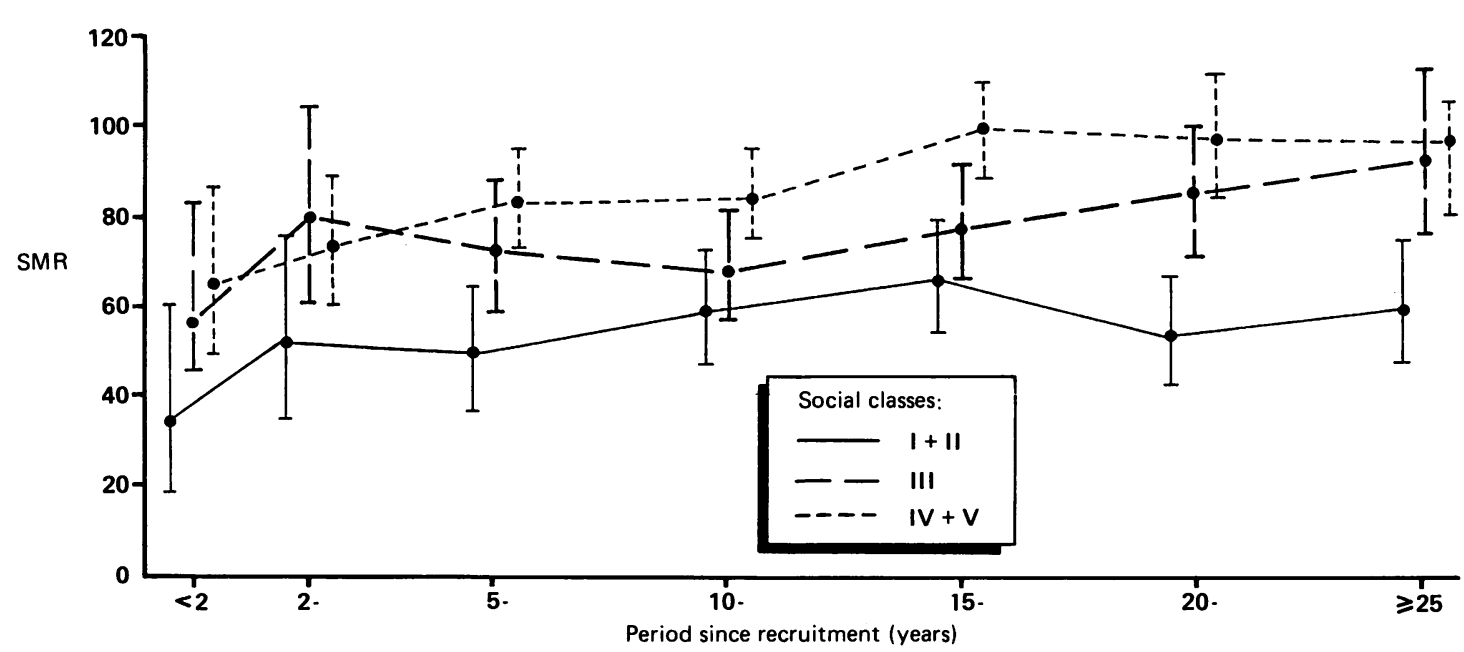

Figure 2 Standardised mortality ratios (with 95\% confidence intervals) for all causes of death except cancer by period since recruitment and social class. 
Table 3 SMRs and observed deaths (O) from all cancers in the UKAEA workforce, 1946-79, by period since recruitment amd duration of employment

\begin{tabular}{|c|c|c|c|c|c|c|c|c|c|}
\hline & & \multicolumn{7}{|c|}{ Period since recruitment $(y)$} & \multirow[b]{2}{*}{ Total } \\
\hline \multicolumn{2}{|c|}{ Duration of employment (y) } & $<2$ & $2-$ & $5-$ & 10 & $15-$ & $20-$ & $\geqslant 25$ & \\
\hline $\begin{array}{c}<2 \\
2- \\
5- \\
10- \\
15- \\
20- \\
25-\end{array}$ & $\begin{array}{l}\text { SMR (O) } \\
\text { SMR (O) } \\
\text { SMR (O) } \\
\text { SMR (O) } \\
\text { SMR (O) } \\
\text { SMR (O) } \\
\text { SMR (O) }\end{array}$ & $\begin{array}{l}69(33) \\
= \\
= \\
= \\
=\end{array}$ & $\begin{array}{l}84(16) \\
82(54) \\
= \\
= \\
=\end{array}$ & $\begin{array}{l}93(37) \\
73(20) \\
77(88) \\
= \\
= \\
-\end{array}$ & $\begin{array}{l}105(50) \\
75(23) \\
120(56) \\
80(84) \\
= \\
=\end{array}$ & $\begin{array}{l}76(35) \\
85(25) \\
91(38) \\
79(36) \\
71(58) \\
=\end{array}$ & $\begin{array}{l}72(25) \\
83(16) \\
80(19) \\
122(28) \\
112(34) \\
73(35) \\
-\end{array}$ & $\begin{array}{c}65(18) \\
94(14) \\
114(14) \\
64(8) \\
99(14) \\
132(22) \\
58(17)\end{array}$ & $\begin{array}{l}81(214) \\
81(152) \\
90(215) \\
85(162) \\
83(100) \\
89(57) \\
58(17)\end{array}$ \\
\hline Total & $\operatorname{SMR}(O)$ & $69(33)$ & $82(70)$ & $80(145)$ & $93(213)$ & $78(192)$ & $88(157)$ & $84(107)$ & $84(917)$ \\
\hline
\end{tabular}

erally similar for social classes (fig 2). SMRs for social classes I and II were consistently lower than those of the remaining classes. In contrast with social class III, SMRs for other classes (social classes I and II combined and social classes IV and V combined) did not increase across the last two period since recruitment strata.

SMRs by period since recruitment and duration of employment are presented in table 3 for cancer mortality and in table 4 for all other causes of death. In both tables, although the variation is substantial, SMRs tend to increase with period since recruitment within each duration of employment stratum with the lowest SMRs tending to fall on the main diagonal. Data in these cells are contributed by individuals either while they were in employment or shortly after they had ended employment. When the data were analysed by period since termination of employment (table 5), SMRs were found to be particularly low in current employees but high in those who had recently left.

In analyses based on data on all employees SMRs were highest in the two years immediately after termination of employment for both cause of death categories (table 5). SMRs for cancer mortality decreased during the first five years after termination of employment and during the first two years for all other causes. Analyses were repeated excluding "normal retirees"- that is, by restricting data to individuals leaving before normal retirement agewhen this was taken to be 65 for men and 60 for women (table 5). SMRs for these individuals were generally below 100, apart from the first two years after termination of employment when SMRs were particularly high $(S M R=167,95 \%$ CI 131-211 for all cancers; $S M R=150,95 \%$ CI $129-174$ for all other causes of death).

The analyses in table 1 identified social class and age at death as significant predictors of the SMR for both cause of death categories. SMRs for causes of death other than cancer also varied significantly according to UKAEA establishment and calendar period of death. While these are interesting findings, such associations potentially confound the analyses of SMRs according to other factors, such as period since recruitment. ${ }^{28}$ Tables 6 and 7 show the results of analyses according to period since recruitment, duration of employment, and period since termination of employment (excluding normal retirees) adjusted for social class alone and adjusted for all the factors analysed in table 1-age at death, sex, calendar period of death, UKAEA establishment, and social class. Also shown are the earlier unadjusted results, expressed in a similar form-as relative SMRs (RSMRs) where the lowest stratum of each factor is taken as the baseline category for that factor.

Adjustment for social class alone produced a slight increase in the RSMR for all cancers with period since recruitment when compared with the unadjusted estimates (table 6), although the trend remained non-significant. Additional adjustment for all confounding factors reduced RSMRs such that, as

Table 4 SMRs and observed deaths (O) from all causes of death other than cancer in the UKAEA workforce, 1946-79, by period since recruitment and duration of employment

\begin{tabular}{|c|c|c|c|c|c|c|c|c|c|}
\hline & & \multicolumn{7}{|c|}{ Period since recruitment $(y)$} & \multirow[b]{2}{*}{ Total } \\
\hline \multicolumn{2}{|c|}{ Duration of employment (y) } & $<2$ & $2-$ & $5-$ & 10 & $15-$ & 20 & $\geqslant 25$ & \\
\hline $\begin{array}{c}<2 \\
2- \\
5- \\
10- \\
15- \\
20- \\
25-\end{array}$ & $\begin{array}{l}\text { SMR (O) } \\
\text { SMR (O) } \\
\text { SMR (O) } \\
\text { SMR (O) } \\
\text { SMR (O) } \\
\text { SMR (O) } \\
\text { SMR (O) }\end{array}$ & $\begin{array}{l}55(86) \\
= \\
= \\
=\end{array}$ & $\begin{array}{l}90(52) \\
65(128) \\
= \\
= \\
= \\
-\end{array}$ & $\begin{array}{l}84(92) \\
77(65) \\
68(220) \\
= \\
= \\
-\end{array}$ & $\begin{array}{l}90(115) \\
74(70) \\
78(114) \\
64(178) \\
- \\
-\end{array}$ & $\begin{array}{l}79(100) \\
90(79) \\
82(114) \\
93(127) \\
78(163) \\
- \\
-\end{array}$ & $\begin{array}{r}80(80) \\
71(41) \\
100(85) \\
86(83) \\
66(46) \\
70(84) \\
-\end{array}$ & $\begin{array}{l}93(72) \\
88(37) \\
92(36) \\
64(32) \\
76(35) \\
88(40) \\
70(50)\end{array}$ & $\begin{array}{l}79(597) \\
75(420) \\
78(569) \\
75(420) \\
75(244) \\
75(124) \\
70(50)\end{array}$ \\
\hline Total & $\operatorname{SMR}(O)$ & $56(86)$ & $71(180)$ & $73(377)$ & $74(477)$ & $84(583)$ & 79 (419) & $81(302)$ & $76(2424)$ \\
\hline
\end{tabular}


Table 5 SMRs and observed deaths (O) for all cancers and all other causes of death in the UKAEA workforce, 1946-79, by. period since termination of employment

\begin{tabular}{|c|c|c|c|c|}
\hline \multirow[b]{2}{*}{$\begin{array}{l}\text { Period since termination } \\
\text { of employment }(y)\end{array}$} & \multicolumn{2}{|l|}{ All employees } & \multicolumn{2}{|c|}{ Excluding normal retirees† } \\
\hline & $\begin{array}{l}\text { Cancer mortality } \\
S M R(O)\end{array}$ & $\begin{array}{l}\text { All other causes of death } \\
S M R(O)\end{array}$ & $\begin{array}{l}\text { Cancer mortality } \\
S M R(O)\end{array}$ & $\begin{array}{l}\text { All other causes of death } \\
S M R(O)\end{array}$ \\
\hline $\begin{array}{c}0^{\star} \\
<2 \\
2- \\
5- \\
10- \\
15- \\
20- \\
25-\end{array}$ & $\begin{array}{c}60(234) \\
140(120) \\
100(122) \\
95(176) \\
92(127) \\
78(70) \\
86(45) \\
72(23)\end{array}$ & $\begin{array}{c}56(595) \\
112(274) \\
86(303) \\
82(461) \\
83(358) \\
85(228) \\
80(121) \\
93(83)\end{array}$ & $\begin{array}{c}-(-) \\
167(71) \\
89(58) \\
93(105) \\
89(94) \\
73(59) \\
84(43) \\
73(23)\end{array}$ & $\begin{array}{c}-(-) \\
149(179) \\
99(177) \\
82(248) \\
82(227) \\
79(171) \\
77(109) \\
94(83)\end{array}$ \\
\hline
\end{tabular}

* Mortality among employees who were employed at time of death.

+Analyses restricted to individuals leaving before normal retirement age, taken as 65 for men and 60 for women.

for the unadjusted analyses, there was little evidence of a trend in RSMR for all cancers with increasing period since recruitment. Adjustment for social class alone had a similar effect on the analyses of cancer mortality by duration of employment (table 6), with the adjusted RSMRs being generally increased relative to the unadjusted figures. Nevertheless, the trend in RSMR for all cancers with duration of employment remained clearly non-significant regardless of the adjusting factors used. The analyses of cancer mortality according to period since termin- $N$ ation of employment were rather less affected by the different adjustments considered. RSMRs from allo analyses fell sharply across the first two strata of period since termination but remained relatively $\frac{D}{2}$ stable thereafter. This pattern was reflected in the statistically significant chi-squared statistics for $\overrightarrow{0}$ departures from trend as well as those for trend in analyses according to period since termination.

The results for causes of death other than cancer

Table 6 Relative standardised mortality ratios (RSMR) (and 95\% confidence intervals) for all cancers in the UKAEA workforce, 1946-79, by period since recruitment, duration of employment, and period since termination of employment (excluding normal retirees), with and without adjustment for age, sex, calendar period of death, UKAEA establishment, and social class

\begin{tabular}{|c|c|c|c|}
\hline & \multicolumn{3}{|c|}{$R S M R(95 \%$ confidence interval) adjusted for } \\
\hline & Unadjusted & Social class alone & $\begin{array}{l}\text { Age, sex, calendar period, } \\
U K A E A \text { establishment, } \\
\text { and social class }\end{array}$ \\
\hline $\begin{array}{l}\text { Period since recruitment }(\mathrm{y}) \\
<2 \\
2- \\
5- \\
10- \\
15- \\
20- \\
25- \\
\chi^{2} \text { for trend }(\mathrm{df}=1) \\
\chi^{2} \text { for departures from trend }(\mathrm{df}=5)\end{array}$ & $\begin{array}{l}1 \cdot 0 \\
1 \cdot 2(0 \cdot 8,1 \cdot 8) \\
1 \cdot 1(0 \cdot 8,1 \cdot 7) \\
1 \cdot 3(0 \cdot 9,1 \cdot 9) \\
1 \cdot 1(0 \cdot 8,1 \cdot 6) \\
1 \cdot 3(0 \cdot 9,1 \cdot 8) \\
1 \cdot 2(0 \cdot 8,1 \cdot 8) \\
0 \cdot 4(p=0.53) \\
4 \cdot 6(p=0.47)\end{array}$ & $\begin{array}{l}1 \cdot 0 \\
1 \cdot 2(0 \cdot 8,1 \cdot 6) \\
1 \cdot 2(0 \cdot 8,1 \cdot 7) \\
1 \cdot 4(0 \cdot 9,1 \cdot 9) \\
1 \cdot 2(0 \cdot 8,1 \cdot 7) \\
1 \cdot 4(0 \cdot 9,2 \cdot 0) \\
1 \cdot 3(0 \cdot 9.1 \cdot 9) \\
2 \cdot 0(p=0 \cdot 16) \\
4 \cdot 2(p=0 \cdot 52)\end{array}$ & $\begin{array}{l}1 \cdot 0 \\
1 \cdot 2(0.8,1 \cdot 8) \\
1 \cdot 1(0 \cdot 8,1 \cdot 6) \\
1 \cdot 3(0.9,1.9) \\
1 \cdot 1(0 \cdot 7,1 \cdot 6) \\
1 \cdot 2(0.8,1.9) \\
1 \cdot 1(0.7,1 \cdot 7) \\
0.0(-) \\
4.6(p=0.47)\end{array}$ \\
\hline $\begin{array}{l}\text { Duration of employment }(\mathrm{y}) \\
<2 \\
2- \\
5- \\
10- \\
15- \\
20- \\
25-\end{array}$ & $\begin{array}{l}1 \cdot 0 \\
1 \cdot 0(0 \cdot 8,1 \cdot 2) \\
1 \cdot 1(0.9,1 \cdot 3) \\
1 \cdot 1(0 \cdot 9,1 \cdot 3) \\
1 \cdot 0(0 \cdot 8,1 \cdot 3) \\
1 \cdot 1(0 \cdot 8,1 \cdot 5) \\
0 \cdot 7(0 \cdot 4,1 \cdot 2) \\
0 \cdot 0(-) \\
4 \cdot 4(\mathrm{p}=0.49)\end{array}$ & $\begin{array}{l}1 \cdot 0 \\
1 \cdot 0(0 \cdot 8,1 \cdot 2) \\
1 \cdot 1(0.9,1.4) \\
1 \cdot 1(0.9,1.4) \\
1 \cdot 1(0.9,1 \cdot 4) \\
1 \cdot 3(0.9,1 \cdot 7) \\
0.9(0.5,1 \cdot 4) \\
1 \cdot 3(p=0.25) \\
3 \cdot 5(p=0.62)\end{array}$ & $\begin{array}{l}1 \cdot 0 \\
1 \cdot 0(0.8,1 \cdot 2) \\
1 \cdot 1(0.9,1 \cdot 4) \\
1 \cdot 1(0.9,1 \cdot 4) \\
1 \cdot 1(0.9,1 \cdot 4) \\
1 \cdot 2(0.9,1 \cdot 7) \\
0 \cdot 8(0.5,1 \cdot 4) \\
0 \cdot 9(p=0.34) \\
3 \cdot 5(p=0.62)\end{array}$ \\
\hline $\begin{array}{l}\text { Period since termination of employment }(y) \\
<2 \\
2- \\
5- \\
10- \\
15- \\
20- \\
25- \\
\chi^{2} \text { for trend }(\mathrm{df}=1) \\
\chi^{2} \text { for departures from trend }(\mathrm{df}=5)\end{array}$ & $\begin{array}{l}1.0 \\
0.5(0.4,0.7) \\
0.6(0.4,0.7) \\
0.5(0.4,0.7) \\
0.4(0.3,0.6) \\
0.5(0.3,0.6) \\
0.4(0.3,0.7) \\
12.5(\mathrm{p}<0.001) \\
14.6(\mathrm{p}=0.01)\end{array}$ & $\begin{array}{l}1.0 \\
0.5(0.4,0.7) \\
0.6(0.4,0.7) \\
0.5(0.4,0.7) \\
0.4(0.3,0.6) \\
0.5(0.3,0.7) \\
0.4(0.3,0.7) \\
14.0(\mathrm{p}<0.001) \\
14.7(\mathrm{p}=0.01)\end{array}$ & $\begin{array}{l}1.0 \\
0.5(0.4,0.8) \\
0.5(0.4,0.7) \\
0.5(0.3,0.7) \\
0.4(0.3,0.6) \\
0.4(0.3,0.7) \\
0.3(0.2,0.6) \\
16.8(\mathrm{p}<0.001) \\
13.5(\mathrm{p}=0.02)\end{array}$ \\
\hline
\end{tabular}


Table 7 Relative standardised mortality ratios (RSMR) (and $95 \%$ confidence intervals) for all causes of death other than cancer in the UKAEA workforce, 1946-79, by period since recruitment, duration of employment, and period since termination of employment (excluding normal retirees), with and without adjustment for age, sex, calendar period of death, UKAEA establishment, and social class

\begin{tabular}{|c|c|c|c|}
\hline & \multicolumn{3}{|c|}{ RSMR (95\% confidence interval) adjusted for } \\
\hline & Unadjusted & Social class alone & $\begin{array}{l}\text { Age, sex, calendar period, } \\
\text { UKAEA establishment, } \\
\text { and social class }\end{array}$ \\
\hline $\begin{array}{l}\text { Period since recruitment }(\mathrm{y}) \\
<2 \\
2- \\
5- \\
10- \\
15- \\
20- \\
25- \\
\chi^{2} \text { for trend }(\mathrm{df}=1) \\
\chi^{2} \text { for departures from trend }(\mathrm{df}=5)\end{array}$ & $\begin{array}{l}1.0 \\
1.3(1 \cdot 0,1 \cdot 6) \\
1.3(1 \cdot 1,1 \cdot 7) \\
1 \cdot 3(1 \cdot 1,1 \cdot 7) \\
1.5(1 \cdot 2,1 \cdot 9) \\
1.4(1 \cdot 1,1 \cdot 8) \\
1.5(1 \cdot 2,1 \cdot 9) \\
11 \cdot 1(\mathrm{p}=0.001) \\
7.3(\mathrm{p}=0.20)\end{array}$ & $\begin{array}{l}1 \cdot 0 \\
1.3(1 \cdot 0,1 \cdot 6) \\
1.3(1 \cdot 0,1 \cdot 7) \\
1 \cdot 3(1 \cdot 1,1 \cdot 7) \\
1.5(1 \cdot 2,1.9) \\
1.5(1 \cdot 2,1.9) \\
1 \cdot 6(1 \cdot 2,2 \cdot 0) \\
18.8(\mathrm{p}<0.001) \\
5.8(\mathrm{p}=0.33)\end{array}$ & $\begin{array}{l}1 \cdot 0 \\
1 \cdot 2(1 \cdot 0,1 \cdot 6) \\
1 \cdot 2(1 \cdot 0,1 \cdot 6) \\
1 \cdot 3(1 \cdot 0,1 \cdot 6) \\
1 \cdot 5(1 \cdot 1,1 \cdot 9) \\
1 \cdot 5(1 \cdot 1,2 \cdot 0) \\
1 \cdot 6(1 \cdot 2,2 \cdot 2) \\
12.5(\mathrm{p}<0.001) \\
3.8(\mathrm{p}=0.58)\end{array}$ \\
\hline $\begin{array}{l}\text { Duration of employment }(y) \\
<2 \\
2- \\
5- \\
10- \\
15- \\
20- \\
25- \\
\chi^{2} \text { for trend }(\mathrm{df}=1) \\
\chi^{2} \text { for departures from trend }(\mathrm{df}=5)\end{array}$ & $\begin{array}{l}1.0 \\
0.9(0.8,1 \cdot 1) \\
1.0(0.9,1 \cdot 1) \\
0.9(0.8,1 \cdot 1) \\
0.9(0.8,1 \cdot 1) \\
1 \cdot 0(0.8,1 \cdot 2) \\
0.9(0.7,1 \cdot 2) \\
0.8(\mathrm{p}=0.37) \\
1.6(\mathrm{p}=0.90)\end{array}$ & $\begin{array}{l}1.0 \\
0.9(0.9,1.3) \\
1.0(0.9,1.1) \\
1.0(0.9,1.1) \\
1.0(0.9,1.2) \\
1.1(0.9,1.3) \\
1.1(0.8,1.5) \\
1.3(\mathrm{p}=0.25) \\
1.8(\mathrm{p}=0.88)\end{array}$ & $\begin{array}{l}1.0 \\
0.9(0.8,1 \cdot 1) \\
0.9(0.8,1 \cdot 1) \\
0.9(0.8,1.0) \\
0.9(0.8,1 \cdot 1) \\
1.0(0.8,1.2) \\
1.0(0.7,1.3) \\
0.3(\mathrm{p}=0.58) \\
3.1(\mathrm{p}=0.69)\end{array}$ \\
\hline $\begin{array}{l}\text { Period since termination of employment }(\mathrm{y}) \\
<2 \\
2- \\
5- \\
10- \\
15- \\
20- \\
25- \\
\chi^{2} \text { for trend }(\mathrm{df}=1) \\
\chi^{2} \text { for departures from trend }(\mathrm{df}=5)\end{array}$ & $\begin{array}{l}1.0 \\
0.7(0.5,0.8) \\
0.6(0.5,0.7) \\
0.6(0.5,0.7) \\
0.5(0.4,0.7) \\
0.5(0.4,0.7) \\
0.6(0.5,0.8) \\
17.4(\mathrm{p}<0.001) \\
33.2(\mathrm{p}<0.001)\end{array}$ & $\begin{array}{l}1.0 \\
0.7(0.5,0.8) \\
0.5(0.4,0.7) \\
0.5(0.4,0.6) \\
0.5(0.4,0.6) \\
0.5(0.4,0.6) \\
0.6(0.5,0.8) \\
23.7(\mathrm{p}<0.001) \\
33.7(\mathrm{p}<0.001)\end{array}$ & $\begin{array}{l}1.0 \\
0.7(0.5,0.8) \\
0.5(0.4,0.7) \\
0.5(0.4,0.7) \\
0.5(0.4,0.7) \\
0.5(0.4,0.7) \\
0.6(0.5,0.9) \\
12.0(\mathrm{p}<0.001) \\
36.0(\mathrm{p}<0.001)\end{array}$ \\
\hline
\end{tabular}

* Relative to the SMR in the lowest stratum which is arbitrarily set to 1.00 .

according to period since recruitment were also strengthened by adjustment for social class (table 7). Although adjustment for all potential confounding factors considered resulted in a statistically significantly weaker association, in contrast with the unadjusted estimates, RSMRs from the adjusted analyses increased across all period since recruitment strata. The relatively low mortality from causes of death other than cancer in employees with longest durations of employment obtained from the unadjusted analyses disappeared after adjustment for social class (table 7). Mortality in this cause of death category continued to show no association with duration of employment in the adjusted analyses. As was the case for cancer mortality, regardless of the type of adjustment made, RSMRs for causes other than cancer showed a sharp decline after the first two years after termination of employment, with little evidence of a systematic change thereafter.

Similar adjustments were performed for analysis by age at recruitment (not shown). RSMRs for causes of death other than cancer showed no statistically significant association with age at recruitment after adjustment for social class alone $\left(\chi^{2}\right.$ for trend $=1 \cdot 0$, $p=0.32)$ or all confounding factors $\left(\chi^{2}\right.$ for trend $=3.3, p=0.07)$. RSMRs for all cancer remained significantly associated with age at recruitment after adjustment for social class alone $\left(\chi^{2}\right.$ for trend $=7 \cdot 1, \mathrm{p}=0.01$ ) but not after adjustment for all confounding factors $\left(\chi^{2}\right.$ for trend $=3 \cdot 6$, $\mathrm{p}=0.06$ ), although RSMRs for older recruits remained higher $(\mathrm{RSMRs}=1.00,1.45,1.59,1.74$, 1.75 , and 2.35 for the respective age at recruitment strata).

In the analyses described above duration of employment was treated as a time dependent variable-that is, an individual employed for ten years contributed person-years at risk to each of the duration of employment strata $<2$ years, 2-4, 5-9, and 10-14 years. This method is compatible with that used in other studies ${ }^{11}{ }^{15}$ but suffers from the criticism that an individual employed for ten years could not have died during the first ten years after entry to the industry. ${ }^{29}$ To overcome this problem, SMRs were recalculated according to final duration of employment category using data only on individuals who had terminated employment. These analyses were confined to the period five or more years after 
Table 8 SMRs and observed deaths (O) for all cancers and all other causes of death in the UKAEA workforce, 1946-79, by final duration of employment assessed at five or more years after termination of employment

\begin{tabular}{lcll}
\hline & Cancer mortality & $\begin{array}{l}\text { All other } \\
\text { causes of death }\end{array}$ \\
\cline { 2 - 2 } $\begin{array}{l}\text { Final duration of } \\
\text { employment }(y)\end{array}$ & $S M R(O)$ & & $S M R(O)$ \\
\hline$<2$ & $85(163)$ & $86(451)$ \\
$2-$ & $82(85)$ & & $81(251)$ \\
$5-$ & $99(100)$ & & $84(285)$ \\
$10-$ & $86(54)$ & & $83(181)$ \\
$15-$ & $103(38)$ & $74(83)$ \\
$\chi^{2}$ for trend (df $\left.=1\right)$ & $1 \cdot 1(\mathrm{p}=0.29)$ & $0.8(\mathrm{p}=0.37)$ \\
$\chi^{2}$ for departures from trend & $1.7(\mathrm{p}=0.64)$ & $0.9(\mathrm{p}=0.83)$ \\
(df = 3) & & \\
\hline
\end{tabular}

termination so as to control for the initial period of high mortality in leavers. The results of these analyses (table 8) confirm the low mortality in short term employees and the general lack of association found earlier between mortality and duration of employment for both causes of death categories.

\section{Discussion}

The analyses described here show that several factors are associated with the level of mortality of the UKAEA workforce when compared with national rates. These may be divided into two groups. The first are sociodemographic factors and health related behaviours that characterise this particular workforce and determine the overall level of death rates observed. The second group relate to the selection of healthy individuals during the employment process which includes both self selection and selection on the part of the employers. One effect of the sociodemographic factors is evident in the statistically significant differences observed in SMRs by social class and UKAEA establishment. The different establishments are located in different parts of the country. The highest SMR for causes of death other than cancer was at Dounreay, located in Scotland, where death rates from these causes are higher than those of England and Wales. ${ }^{30}$ SMRs were lowest for social classes I and II which have lower than average death rates. ${ }^{30}$ Most of the workforce was located in the south of England at Harwell and Winfrith ${ }^{17}$ where death rates are lower than average $^{30}$ and included a larger than average proportion of individuals from higher social classes. ${ }^{17}$ Both these factors will have contributed to the generally low SMRs observed in the workforce. It is also possible that differences in health related behaviour, such as smoking or alcohol consumption, between the employees and the general population may have further contributed to its favourable mortality experience. Data on such factors were not available here and so their effects cannot be assessed.

The second group of factors associated with the level of mortality in the workforce are those relevant $\stackrel{0}{\circ}$ to the initial selection of healthy individuals into the $\overrightarrow{\vec{F}}$ workforce. In contrast to sociodemographic and lifestyle factors, health related selection has a dyn- $\frac{C}{0}$ amic effect on death rates and must therefore be $\frac{\bar{c}}{\bar{c}}$. studied by analyses involving time dependent factors $\frac{\pi}{\widetilde{\sigma}}$ such as period since recruitment. Data on the $\varrho$ UKAEA workforce are ideal for studying time os dependent determinants of occupational mortality $\vec{\circ}$ because all individuals in the study population were followed up from their data of first employment. $\vec{\omega}$ Also, the size of the workforce, consisting of nearly 40000 individuals, provides sufficient numbers of $\frac{\Phi}{3}$ deaths and person-years at risk for the simultaneous investigation of the effects of more than one time. dependent factor. Moreover, because the effect of $i$ exposure to radiation was not found to have an effect $\stackrel{\vec{\infty}}{\circ}$ on overall death rates, analyses involving time depen-응 dent factors are unlikely to be confounded by the $\overrightarrow{ }$ effects of work related exposures. ${ }^{1215}$

SMRs for all cancers and all other causes of death were lowest during the first two years after recruit- $\vec{\bullet}$ ment, representing death rates that were, respec- 8 tively, $31 \%($ SMR $=69,95 \%$ CI 48-97) and $45 \%$. $(S M R=55,95 \%$ CI 44-69) lower than national rates. In univariate analyses period since recruitment was significantly associated with increasing mortality from causes other than cancer but not from cancer $\stackrel{2}{\circ}$ mortality. The results from the adjusted analysis $\unrhd$ were generally similar although, in contrast with the $\overrightarrow{\vec{O}}$ unadjusted results, mortality from causes other than 3 cancer increased across all period since recruitment $\vec{F}$ strata. A continued increase in mortality throughout the follow up period was observed only in social class $\bar{O}$ 3 (fig 2). One explanation for this differential pattern might be that highest and lowest social classes are more prone to biases arising from loss to follow up. The higher social classes in this workforce included $\delta$ many scientists who are more likely to have emigrated than other workers (L Salmon, personal o communication). Since emigrations from the United? Kingdom are underreported (P Goldblatt, personal on communication) many of these individuals may therefore contribute person-years at risk whereas any $ᄋ$ deaths that occurred among them are unlikely to have $N$ been notified and included in the study. The reason $\mathrm{W}_{\mathrm{W}}$ for poorer follow up in social classes IV and V is less $\sigma$ likely to be due to emigration but possibly reflects the generally greater difficulties in linkage of records in these classes (P Goldblatt). Thus insofar as increases $\stackrel{\mathbb{\infty}}{\rightarrow}$ in mortality with period since recruitment reflect the initial selection of healthy individuals into the workforce, these data suggest that health related selection $\mathbb{\mathbb { D }}$ continues to exert an effect on death rates for causes

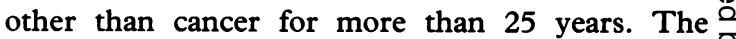
contrasting limited increase in cancer mortality with period since recruitment lends support to the sugges- $\delta$ tion from data on other workforces that selection on 
Duration of employment showed little association with mortality for either cause of death category, thus providing little evidence for a survivor effect whereby individuals who remain in employment experience lower mortality than those who leave. In particular, contrary to the findings in other workforces, ${ }^{1131}$ there was no suggestion that short term workers had higher mortality than other workers.

Evidence for the selection out of employment of individuals due to ill health was provided by an examination of mortality by period since terminating employment. SMRs were found to be lowest of all in current employees but highest in those who had left recently. When data were confined to individuals leaving before normal retirement age, SMRs were high during the first two years after termination for mortality from cancer (SMR $=167,95 \%$ CI 131211) and for all causes except cancer $(S M R=149$, $95 \%$ CI 128-173). By comparison, mortality for later periods was significantly lower for both cause of death categories and remained relatively constant with increasing period since termination regardless of the adjustment made for confounding factors. These analyses support the suggestion that the effect on death rates of selection of individuals out of employment due to ill health is confined to only the first few years after termination of employment. ${ }^{29}$ This general pattern is similar to that found in another nuclear industry workforce ${ }^{11}$ but our data do not exhibit the continued excess of cancer mortality in leavers found there.

The initial trend of increasing SMR with age at recruitment for causes other than cancer appeared to be explained largely by confounding by social class. This agrees with the lack of association between all cause mortality and age at recruitment in data on rubber workers. ${ }^{3}$ The stronger association observed for cancer mortality did not disappear after adjustment for social class and remained marginally significant after adjustment for all confounding factors. The reason for this differential pattern is unclear and, since similar analyses have rarely been reported, is difficult to interpret. One reason considered was that older recruits might be more susceptible to the carcinogenic effects of radiation, although empirical evidence to support an association of increasing radiosensitivity with increasing age at first exposure is not strong. ${ }^{32}$ Moreover, when analyses were carried out separately for workers who had radiation records and other workers (not shown), SMRs for all cancers increased in a similar way with age at recruitment, suggesting that radiation exposure is an unlikely explanation.

Whereas the level of mortality in an occupational cohort is likely to depend on its sociodemographic and other health related characteristics, the way in which death rates change with time may follow a common pattern determined by the processes of health related selection. Relevant analyses from other occupational cohorts are still relatively few so this is difficult to assess at present. Analyses such as those described here are useful as they increase our general understanding of the processes of health related selection during employment. They have the important additional benefit of identifying potential confounders for consideration when investigating exposure effects in individual occupational mortality studies.

Members of the Epidemiological Monitoring Unit are funded by the Medical Research Council through contracts held with the United Kingdom Atomic Energy Authority. We thank the members of these two organisations without whose support and cooperation the study would not have been possible. We also thank David Leon, Geoffrey Rose, Michael Hills, Martin Shipley, and Charles Rossiter for useful discussions that helped in the development of the ideas and methods expressed in this paper, Martin Gardner for comments on an earlier draft, and Anna Brown for computing help.

1 Fox AJ, Collier PF. Low mortality rates in industrial cohort studies due to selection for work and survival in the industry. Br J Prev Soc Med 1976;30:225-30.

2 McMichael AJ. Standardised mortality ratios and the "healthy worker effect": scratching beneath the surface. J Occup Med 1976;18:165-8.

3 Monson RR. Observations on the healthy worker effect. JOccup Med 1986;28:425-33.

4 Pearce N, Checkoway $\mathrm{H}$, Shy C. Time-related factors as potential confounders and effect modifiers in studies based on an occupational cohort. Scand J Work Environ Health 1986;12:97-107.

5 Tola S, Hernberg S. Healthy worker effect. In: Chiazze L, Lundin FE, Watkins D, eds. Methods and issues in occupational and environmental epidemiology. Ann Arbor, Michigan: Ann Arbor Science, 1983:85-92.

6 Carpenter L. Some observations on the healthy worker effect. $\mathrm{Br}$ $J$ Ind Med 1987;37:11-24.

7 Hernberg $S$. "Negative" results in cohort studies-how to recognise fallacies. Scand J Work Environ Health 1981;7(suppl 4):121-6.

8 Seltzer CC, Jablon S. Effects of selection on mortality. Am J Epidemiol 1974;100:367-72.

9 Wang J-D, Miettinen OS. Occupational mortality studies. Principles of validity. Scand J Work Environ Health 1982;8:153-8.

10 Weed DL. An epidemiological application of Popper's method. $J$ Epidemiol Community Health 1985;39:277-85.

11 Gilbert ES. Some confounding factors in the study of mortality and occupational exposures. Am J Epidemiol 1982;116: $177-88$.

12 Howe GR, Chiarelli AM, Lindsay JP. Components and modifiers of the healthy worker effect: evidence from three occupational cohorts and implications for industrial compensation. Am J Epidemiol 1988;128:1364-75.

13 Wilcosky T, Wing S. The healthy worker effect. Selection of workers and workforces. Scand J Work Environ Health 1987;13:70-2.

14 Fox AJ, Goldblatt PO, Adelstein AM. Selection and mortality differentials. J Epidemiol Community Health 1982;36:69-79. 15 Weed DL, Tyroler HA, Shy C. The healthy worker effect in 1987;29:335-9.

16 Bell CMJ, Coleman DA. Models of the healthy worker effect in 
industrial cohorts. Statistics in Medicine 1987;6:901-9.

17 Fraser P, Booth M, Beral V, Inskip H, Firsht S, Speak S. Collection and validation of data in the United Kingdom Atomic Energy Authority mortality study. $\mathrm{Br}$ Med $\mathrm{J}$ 1985;291:435-9.

18 Beral V, Inskip H, Fraser P, Booth M, Coleman D, Rose G. Mortality of employees of the United Kingdom Atomic Energy Authority, 1946-1979. Br Med J 1985;291:440-7.

19 Inskip H, Beral V, Fraser P, Booth M, Coleman D, Brown A. Further assessment of the effects of occupational radiation exposure in the United Kingdom Atomic Energy Authority mortality study. $B r J$ Ind Med 1987;44:149-60.

20 Beral V, Carpenter L, Booth M, Inskip H, Brown A. The "healthy worker effect" and other determinants of mortality in workers in the nuclear industry. In: Health effects of low dose ionising radiation-recent advances and their implications. Proceedings of the British Nuclear Energy Society conference, London, 1987. London: British Nuclear Energy Society, 1988.

21 Berry $\mathrm{G}$. The analysis of mortality by the subject-years method. Biometrics 1983;39:173-84.

22 Office of Population Censuses and Surveys. Classification of Occupations 1970. London: HMSO, 1970.

23 World Health Organisation. International classification of diseases. 8th rev. Geneva; WHO, 1967.

24 Bailar JC, Ederer F. Significance factors for the ratio of a Poisson variable to its expectation. Biometrics 1964;20:639-43.
25 Baker RJ, Francis B, Green M, et al. The GLIM System (release? 3.77) user's guide. Oxford: Numerical Algorithms Group, $\vec{\nexists}$ 1985.

26 McCullagh P, Nelder JA. Generalised linear models. London: Chapman and Hall, 1983.

27 Breslow NE, Lubin JH, Marek P, Langholtz B. Multiplicative 흐 models and cohort analysis. Journal of the American Statistical $\bar{\omega}$ Association 1983;78:1-12.

28 Breslow NE, Day NE. The standardised mortality ratio. In: Sen $\stackrel{\mathbb{Q}}{\Omega}$ PK, ed. Biostatistics: statistics in biomedical, public health and
environmental sciences. New York: Elsevier, 1985:55-74.

29 Fox AJ. Vinyl chloride and mortality. Lancet 1976;ii:416-7.

30 Office of Population Censuses and Surveys. Occupational mortality: the Registrar General's decennial supplement 1970-72. London: HMSO, 1978. (Series DS No 1.)

31 McDonald AD, Fry JS, Wooley AJ, McDonald JC. Dust exposure and mortality in an American chrysotile asbestos $O$ friction products plant. Br J Ind Med 1984;41:151-7.

32 Beebe GW. Developments in assessing carcinogenic risks from? radiation. In: Boice JD, Fraumeni JF, eds. Radiation carcinogenesis: epidemiology and biological significance. New York:Raven Press, 1984:457-66.

Accepted 17 July 1989

\section{Correspondence and editorials}

The British Journal of Industrial Medicine welcomes correspondence relating to any of the material appearing in the journal. Results from preliminary or small scale studies may also be published in the correspondence column if this seems appropriate. Letters should be not more than 500 words in length and contain a minimum of references. Tables and figures should be kept to an absolute minimum. Letters are accepted on the understanding that they may be subject to editorial revision and shortening.

The journal now also publishes editorials which are normally specially commissioned. The Editor welcomes suggestions regarding suitable topics; those wishing to submit an editorial, however, should do so only after discussion with the Editor. 